\title{
Scholarly open-access publishing and the problem of predatory publishers
}

\section{Jeffrey Beall}

\author{
Auraria Library, University of Colorado Denver, 1100 Lawrence St. Denver, Colo. 80204, USA
}

Scholars today need new skills to thrive and even survive in the rapidly-changing world of scholarly publishing. The open-access movement, a worldwide social movement, has intensively promoted the open-access publishing model, in which scholarly articles are freely available to everyone with internet access. Specifically, one of the new, open-access distribution models for scholarly publishing is called gold open-access. ${ }^{1}$ Under this model, the publication is financed by a fee charged to authors upon acceptance of a manuscript. The fee is called the article processing charge (APC), and it can range from a few hundred dollars to a few thousand dollars, depending on the journal and publisher. Most journals published using the gold model are only available online-not in print.

The idea of making scholarship freely available to everyone sounds attractive at first, but often such simply stated ideals are more complex, with unattractive features, when examined more closely. Moreover, great ideas often are poisoned by unintended consequences upon and after their implementation, leaving many to wish for a return to the stability of the former system. Such is the case with scholarly open-access publishing.

This gold open-access model is prone to corruption, and one of the new skills that scholars need is the ability to spot and avoid corrupt scholarly publishers. Gold openaccess turns the traditional subscription model on its head. Instead of library and individual subscriptions funding scholarly publishing, in gold open-access journals the publishing costs are funded by the APCs, a situation that creates a pernicious conflict of interest for the open-access publishers. Their income is gauged to the number of papers they accept and publish, so if they publish more, they earn more.

Accordingly, the model has fostered the creation of an increasing number of scholarly publishers existing solely for the purpose of earning the article processing charges. In 2010, I coined the term "predatory publishers" [1] to describe them, and the term has become part of the scholarly publishing lexicon. Unlike traditional publishers, which live or die on subscription revenue, gold open-access publishers earn their money from authors. Thus they are author-oriented rather than reader oriented. Subscription journals that publish lowquality articles will, over time, find themselves losing subscribers, especially given tight library budgets. On the other hand, gold open-access publishers need not worry about this, for they have no subscribers. Their content is free for anyone to access. They must keep the authors happy, for the authors are the source of their income. So, for them, publishing low-quality work does not affect their income like it does for traditional publishers. In many cases they operate like vanity presses in the literary world, publishing whatever authors pay them to publish.

This focus, unfortunately, has many negative consequences. Authors want a fast and easy publishing process. Increasingly, predatory publishers have emerged that efficiently meet this need, throwing aside the traditions and obligations of honest and rigorous peer review.

Here is how predatory publishers operate. They send out many hundreds of thousands of spam e-mail messages inviting article submissions. For those authors that respond favorably to these e-mails, the publishers quickly accept the papers, sometimes performing only the most perfunctory peer review or not performing one at all (yet claiming to). The papers are published quickly, sometimes in a matter of a few days. The papers appear, the author gets the academic credit, and everyone goes about his way.

Some of the most corrupt publishers do not inform the authors of the required fees, exploiting their ignorance of APCs and sending them an invoice a week after publication. In some cases, the authors have already transferred copyright to the publisher, leaving them with few options.

Sometimes the authors are fooled by the publishers; sometimes they are complicit. I see an increasing number of complicit authors, especially in countries where there is intense competition among scholars and where quantitative measures are used to determine tenure, promotion, and annual salary increases. Predatory publishers expertly mimic legitimate scholarly publishers, using impressive sounding names for their publishing

\footnotetext{
E-mail: jeffrey.beall@ucdenver.edu

1 There are two other open-access models that bear mentioning. The green open-access model refers to authors publishing in a traditional journal and then making a postprint of the work available in an open-access repository. Also, platinum open-access is free to readers and free to authors, with the publishing costs supported by an organization or institution.
} 
operations (such as the American Research Institute for Policy Development) and for their journals (such as Asian Journal of Engineering and Technology). Predatory publishers claim to have valid impact factors, even when they do not. Also, an increasing number of bogus journal impact factor companies are emerging in concert with the predatory publishers to strike a double blow against the conscientious researcher, many of whom are unprepared to deal with a fake journal buoyed by a fake impact factor. A system once founded on trust now requires intense scrutiny to avoid scams.

\section{EFFECTS ON SCIENCE AND SOCIETY}

Because of the predatory publishers' corrupt practices, scholarly communication is now flooded with low quality, unreviewed, and often plagiarized "scholarly" papers. Increasingly, many scholarly articles, especially those published in questionable journals, don't serve to report on new findings or new theories. Instead, they merely serve to help an author get tenure, promotion, or an improved annual evaluation. Too few publishers check for plagiarism before accepting and publishing scholarly manuscripts, resulting in an abundance of copied work being published in many scholarly venues.

More seriously, the publication of so-called scientific papers that did not pass through a proper peer review threatens scientific integrity. One of peer reviewing's roles is to draw a line between authentic science and pseudoscience. For example, a paper reporting on valid research in astronomy will pass peer review and be published, but a paper on astrology, a pseudoscience, will not pass a legitimate peer review. This division is called demarcation. Because of the breakdown of peer review, much pseudoscience is being published. And, because research is cumulativenew research builds on research already recorded in the academic record - the pollution of the scholarly record with pseudoscience threatens all of science and the communication of science.

Scientists are not the only consumers of research. There are several components of society that rely on published research, and these include the press, the legal system and professional practice, such as medicine.

The expression "bench to bedside" refers to research results obtained by a scientist working in a laboratory, at his bench, and the research subsequently being translated into clinical practice by a medical doctor who is at the bedside of a hospital patient. Scientific research directly links to clinical practice, so if bad science enters the process at any point, it can poison the research and directly affect how doctors treat their patients.
Many predatory publishers are actually one-man operations, and they frequently operate out of a dwelling. Using mail forwarding services, they mask their true locations and appear to the world as if they are based in cities such as London or New York. Fearing, probably justifiably, that scholarly authors will be reluctant to submit to a publisher based in India or Nigeria, publishers in these countries frequently deceive potential authors into believing they are in major cities elswhere. Also, because these are ephemeral, one-man operations, they are extremely profit-oriented and invest little in long-term services. One such service is digital preservation, or the redundant backing-up of web-published content.

Few of the small predatory publishers devote any resources to digital preservation, putting their published work at risk of being lost. In fact, some small publishers have already folded, and the journals and articles they published have disappeared from the internet. Thus, for authors who choose to use the gold open-access model, they should only pay fees to publishers that offer longterm stability and a broad array of high quality publishing services. Publishing with small open-access publishers is risky. Larger publishers benefit from economies of scale and are generally better able to provide higher quality and more comprehensive services.

How can we stop predatory publishers? Because they enjoy the freedom of the press, there may be no way to stop them. Instead, scholars must develop and use new skills to identify and avoid questionable publishers. For emerging scholars and even graduate students, training in avoiding scholarly publishing scams - a component of information literacy - is now essential. Also, I maintain a list of predatory publishers on my website, Scholarly Open Access, at http://scholarlyoa.com. The site also includes a list of questionable journals that don't publish as part of any publisher's fleet of journals; they are called standalone journals or mega-journals. The website also includes commentary in the form of regular blog posts about scholarly open-access publishing.

While open-access publishing has opened up research for many, it also has created some very negative consequences, chiefly predatory publishers that exploit researchers and poison scholarly communication. Also, because the predominant type of open-access, the gold model, requires payment from authors, it has shut off many researchers from sharing their research, for they are unable to pay or obtain funding for the fees. On the other hand, authors with extra funds can purchase benefits, such as expedited peer reviews, from some payto-publish journals, likely reducing the effectiveness of peer review. What additional shortcuts will open-access journals make available to authors willing to pay extra? 
Therefore, all scholarly authors should become fully aware of the weaknesses of open-access publishing and avoid submitting their research manuscripts to questionable publishers and journals. By focusing on speed rather than on quality, the quick and easy publishing that predatory publishers offer can hurt researchers in the long run. Quality scholarly publishers add great value to research through a well-managed peer review and copy editing process, a practice that benefits authors - and science itself-over time.

\section{REFERENCE}

1. Beall, J. "Predatory" open-access scholarly publishers. The Charleston Advisor 11 (2010) 10-17. 